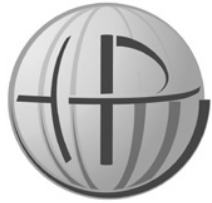

Horyzonty Polityki 2020, Vol. 11, No 37

\section{Magdalena Zdun}

http://orcid.org/0000-0002-3784-2098 Uniwersytet Ekonomiczny w Krakowie Kolegium Gospodarki i Administracji Publicznej magda.zdun@gmail.com

DOI: 10.35765/HP.1986

\title{
Kultura innowacyjności jako wyzwanie dla współczesnego uniwersytetu ${ }^{1}$
}

\section{Streszczenie}

CEL NAUKOWY: Celem analizy jest określenie szans i zagrożeń, roli i miejsca współczesnego uniwersytetu w kontekście wyzwań kultury innowacyjności. Kultura innowacyjności da się rozpoznać jako „środowisko”, w którym akademia funkcjonuje, jak również sposób organizacji samej wszechnicy. Analizowana będzie ona w trzech podstawowych aspektach: materialnym, społecznym i symbolicznym, z uwzględnieniem możliwych do wyróżnienia podtypów.

NARZĘDZIA I METODY BADAWCZE: Metodą badawczą jest analiza pojęć i koncepcji. Praca ma charakter teoretycznej analizy i opiera się na dorobku teorii socjologicznej w tym zakresie. Jej zamierzeniem jest rekonstrukcja pojęcia kultura i powiązanie tego terminu z kategorią innowacyjności. Pozwoli to na identyfikację konkretnych obszarów kultury innowacyjności oraz jej odmian, z którymi zmierzyć musi się współczesna akademia.

PROCES WYWODU: Wywód składa się z trzech części. W pierwszej z nich wprowadzone zostaje pojęcie kultury innowacyjności oraz wskazane zostają płaszczyzny analizy wynikające bezpośrednio z zaproponowanej definicji. Na tym etapie wskazane zostaną również ujęcia oraz dwie podstawowe perspektywy

1 Publikacja została sfinansowana ze środków subwencji przyznanej Uniwersytetowi Ekonomicznemu w Krakowie: Program Potencjał „Rozwój społeczno-gospodarczy w analizach teoretycznych i diagnostyce empirycznej" nr 51/GGG/2020/POT/. 
diagnozy kultury innowacyjności: jednostkowa i systemowa. Odpowiadają one $\mathrm{w}$ przybliżeniu podziałowi na atomizm i holizm w teorii socjologicznej. W etapie drugim przedstawiona zostanie typologia kultur innowacyjności w odniesieniu do terminów: osobliwość i ustrój. Ustalenia te pozwola by w etapie trzecim odnieść kategorię kultury innowacyjności do uniwersytetu.

WYNIKI ANALIZY NAUKOWEJ: Podstawowym wynikiem analizy jest identyfikacja szans i zagrożeń związanych z wdrażaniem się współczesnego uniwersytetu w kulturę innowacyjności. Szanse i zagrożenie dadzą się odnaleźć zarówno w otoczeniu, w którym funkcjonuje akademia, jak również w jego normatywnej, organizacyjnej i technologicznej strukturze.

WNIOSKI, INNOWACJE, REKOMENDACJE: Ostateczne wnioski i rekomendacje związane są z próbą zaprojektowania przyszłości uniwersytetu. Ma być to zarazem organizacja i wspólnota, która wykorzystuje szanse, jakie stwarza kultura innowacyjności, oraz jednocześnie radzi sobie wygenerowanymi przez nią zagrożeniami.

\section{SŁOWA KLuCzowe:}

uniwersytet, innowacyjność kultura, wartości

\section{Abstract \\ CULTURE OF INNOVATION AS A CHALLENGE FOR TODAY'S UNIVERSITIES}

RESEARCH OBJECTIVE: This study seeks to identify the risks and opportunities for, as well as the role and position of, today's universities in relation to the challenges posed by the culture of innovation. The culture of innovation can be described both as an environment in which academia operates, and as a way to organise universities. It will be analysed from three basic perspectives - financial, social, and symbolic, while taking into account any subtypes.

THE RESEARCH PROBLEM AND METHOD: The study will be a discussion of different notions and concepts. This is a theoretical analysis and builds on the relevant advancements in sociological theory. It is intended to revisit the notion of culture and to associate it with innovation. This will help identify some specific areas within, and versions of, the culture of innovation that can be faced by today's academia.

THE PROCESS OF ARGUMENTATION: This study has three parts. The first introduces the notion of innovation culture and identifies the areas of analysis based on the proposed definition. This stage proceeds to describe approaches to, and two perspectives on, the culture of innovation, namely individual and systemic. These more or less correspond to the sociological distinction between 
atomism and holism. Stage two describes the types of innovation cultures based on the notions of originality and organisation. These are used in stage three to explore the culture of innovation in relation to universities.

RESEARCH RESULTS: The primary results of this study are the identified risks and opportunities related to the challenges faced by today's universities in their efforts to foster the culture of innovation. Risks and opportunities can be found both in the environment in which academia operates, and in its normative, organisational, and technological structures.

CONCLUSIONS, INNOVATIONS AND RECOMMENDATIONS: Final conclusions and recommendations are made to build universities of the future. These are to be both organisations and communities, which take advantage of the opportunities offered by the culture of innovation, while also addressing the associated risks.

\section{KeYwORDS:}

innovation, university, culture, values

\section{WPROWADZENIE}

O współczesnym uniwersytecie coraz częściej dyskutuje się w kontekście przedsiębiorczości i innowacyjności. Oznacza to, że zmieniły się wymagania i oczekiwania wobec akademii. Ma ona nie tylko kształcić, pielęgnować tradycję, rozwijać koncepcje i teorie, ale również odpowiadać na konkretne zapotrzebowania płynące ze świata zewnętrznego. Współczesna gospodarka domaga się innowacji. To one są przyczyną wzrostu i gospodarczego powodzenia. Uniwersytet musi się $\mathrm{w}$ związku z tym zmierzyć $\mathrm{z}$ zagadnieniem nowatorstwa.

Celem niniejszej analizy jest diagnoza szans i zagrożeń akademii w kontekście wyzwań, jakie stawia kultura innowacyjności. Określa ona sposób funkcjonowania akademii i rolę badacza w uniwersytecie. W pierwszej kolejności przedmiotem naukowego rozpoznania stanie się samo pojęcie kultury innowacyjności. Da się ono rozpoznać jako kategoria analityczna, a nie oceniająca. Pojęcie to służyć będzie wskazaniu konkretnych sposobów realizowania się uniwersyteckiej innowacyjności. Urzeczywistnienia te wydobyte zostaną na światło dzienne za sprawą adekwatnego narzędzia systematyzacji. Będzie nią typologia kultur innowacyjności. Samo zaś nowatorstwo potraktowane zostanie jako podstawowa kompetencja cywilizacyjna we 
współczesnym świecie. Uniwersytet zdefiniowany zostanie jako instytucja zobowiązana do zagospodarowania innowacyjności, która z jednej strony musi uszanować reguły nowatorstwa, a z drugiej wkomponować je w swoje zasady i etos wiedzy.

\section{METODOLOGIA}

Praca ma charakter teoretyczny. Zastosowaną w niej metodą jest analiza pojęć, koncepcji i stanowisk z zakresu teorii socjologicznej. Diagnozie problemu „innowacyjnego uniwersytetu” służy kategoria kultury innowacyjności oraz powiązana z nią typologia kultur. Pierwsze z wymienionych pojęć będzie pełnić rolę narzędzia analizy, drugie - konceptualnego instrumentu systematyzacji. Proces wywodu składać będzie z kilku powiązanych ze sobą części. W pierwszej zdefiniowana zostanie naczelna kategoria analizy. W drugiej zaprezentowane zostanie narzędzie systematyzacji. Część ostatnia implikuje wcześniejsze ustalenia do rozwiązania problemu „innowacyjnego uniwersytetu".

\section{PROCES WYWODU: KATEGORIA KULTURY INNOWACYJNOŚCI JAKO NARZĘDZIE ANALIZY}

Kultura innowacyjności jest pojęciem wymagającym na wstępie wyjaśnienia. Jego zrozumienie stanowi warunek sine qua non zastosowania w diagnozie. W ślad za Antoniną Kłoskowską (2007, s. 67) przyjąć trzeba, że samo określenie kultura „ma charakter niewartościujący i nieselektywny". Tym samym termin ten pozbawiony zostanie funkcji oceniającej. Służyć ma raczej opisowi, a nie weryfikacji; wyjaśnieniu a nie wydawaniu „cenzurek". „Cały zakres pojęcia [kultura] - tłumaczy Kłoskowska (2007, s. 67) - obejmuje zjawiska bardzo różnorodne, wymagające także rozmaitych kompetencji badawczych." Pojęcie to obejmuje swym zakresem trzy kategorie zjawisk. Odpowiadają one kolejno: materii, działaniom i symbolom. Materia związana jest z bytową kategorią (warstwą) kultury. Kultura bytu obejmuje przez to wszelkie materialne wytwory działalności człowieka. Daje się też opisaćjako obszar środków i zbiór obiektów, służących zaspokojeniu 
podstawowych potrzeb. Z kolei działania są kwintesencją warstwy socjetalnej, znajdującej wyraz w aktywności jednostek, relacjach, jakie one tworza, i rolach, które wykonują. Obszar imponderabiliów to ostatnia ze wskazanych przez Kłoskowską warstw. Określana zostaje mianem symbolicznej. Obejmuje ona sferę wartości i znaków. Te zaś „są przedmiotami lub aktami ludzkiego zachowania, stanowiącymi korelaty postaw i znaczeń (Kłoskowska, 2007, s. 74)". To systemy, „którymi posługuje się człowiek, (...) i matryca, za pomocą której duch ludzki nadaje kształt rzeczywistości" (Kłoskowska, 2007, s. 75).

Treść poszczególnych warstw kultury dookreśla jej terminologiczne dopełnienie. $W$ tym przypadku rolę dopełnienia pełni określenie innowacja. $W$ analizie naukowej pojęciem tym jako pierwsi zaczęli posługiwać się antropolodzy. Przekonali oni, że novum to hybrydowa mieszanka tego, co znane, z tym, co niepewne i wymagające sprawdzenia (Barnett, 1953, s. 181-182). Innowacyjność zaś to poznawcza gotowość do w prowadzania innowacji (Rogers, 1973, s. 248-251). Jednocześnie antropolodzy zauważyli, że innowacja jest narzędziem zmiany społecznej i z tej też przyczyny obciążona jest niepewnością. Jej implementacja i tworzenie wymaga przełamywania barier i podejmowania się ryzyka. Na dodatek novum uposażone zostaje we właściwy tylko sobie przymiot. Jest nim tzw. „,swoista komunikatywność kulturowa” (Linton, 1936, s. 337). Miarą tej cechy jest stopień dopasowania do systemu społecznego, do którego trafia. Największym „kłopotem” dla systemu jest rewolucyjna innowacja. Novum wówczas wymusza na systemie duże działania przystosowawcze. Dopinguje też jednostkę do podjęcia działań „,niecodziennych”, wybijających z kolein rutyny. $Z$ tej też przyczyny jest cennym narzędziem gospodarki. Na ten fakt zwraca uwage Joseph Schumpeter (1960). Jego zdaniem innowacja, pojawiając się w gospodarce, dokonuje "twórczych turbulencji”. Wytrąca system z równowagi i pozawala mu wznieść się na wyższy poziom rozwoju (Schumpeter, 1960, s. 10). Dzięki niej właśnie możliwe jest przejście od „ruchu okrężnego" w stronę stadium dynamicznej gospodarki, w którym władzę zaczynają przejmować przedsiębiorcy (Unternahmer). To oni odpowiadają za rozwój i dlatego obciążeni zostają powinnością generowania oraz rozpowszechniania nowatorstwa (Schumpeter, 1960, s. 129-136, Sombart, 1919, 836). Właściwa przedsiębiorcy innowacyjność wymaga szczególnych przymiotów i talentów, w tym duchowej wolności, która „zakłada dużą nadwyżkę 
siły w stosunku do wymagań dnia powszedniego" (Schumpeter, 1960, 138). Do inicjatywy nowatorskiej motywuje ich nie tyle zysk, ile misja przekształcania świata.

Ustalenia te pozwalają zdefiniować termin bardziej szczegółowy, jakim jest kultura innowacyjności. Kategoria ta łączy w sobie trzy obszary: materialny, socjetalny i symboliczny oraz uwzględnia fakt, że innowacyjność jest rodzajem predyspozycji dającej się przypisać do jednostki, jak i całości społecznej (Zdun, 2016, s. 179-180).

Na kulturę innowacyjności składają się trzy wzajemnie ze sobą powiązane warstwy:

1. materialna (bytowa) - jej treścią są wynalazki, patenty i dostępne $\mathrm{w}$ bezpośrednim doświadczeniu odkrycia. Warstwa ta jest efektem działań aktorów społecznych, śladem po ich aktywności. Jej zasobność świadczy o technologicznym zaawansowaniu, które znajduje przełożenie na dynamikę procesu rozwojowego. Zapleczem teoretycznym tejże warstwy jest determinizm technologiczny i materializm historyczny. Ostatni ze wskazanych nurtów myślowych przyjmuje, że obszar materialny całkowicie determinuje rozwój, a sfera świadomościowa pełni jedynie rolę jego epifenomenu (Szacki, 2012, s. 230). Z kolei przedstawiciele determinizmu technologicznego przekonują, że wynalazki wymuszają na systemie społecznym przystosowanie, przez co osadzone zostają $\mathrm{w}$ roli naczelnej determinanty rozwoju (Ogburn, 1964).

2. so cje talna (społeczna) - jej treścią są działania aktorów społecznych i wykonywane przez nich role $\mathrm{w}$ zakresie nowatorstwa. Analiza tej warstwy opiera się na założeniu, że na „wskaźniki innowacyjności” pracują nie tylko materialne zasoby, ale przede wszystkim ludzie. Dlatego też jej analiza koncentruje się na diagnozie sieci współpracy oraz jakości kapitałów społecznych i ludzkich. Jednocześnie tego typu diagnoza stawia sobie za cel dotarcie do „motywacji innowacyjnej", która jest podstawowym przymiotem aktora „innowacyjnej gospodarki." Motywacja ta - za czym przemawiają klasyczne już dziś badania Davida McClellanda (1973) i Everett Hagena (1962) - jest efektem odziaływań socjalizacyjnych na jednostkę, przyswojonego przez nią 
habitusu. Zapleczem teoretycznym warstwy socjalnej jest koncepcja przedsiębiorczości autorstwa Josepha Schumpetera (1960). Zgodnie z nią innowacyjność jest signum specificum mocnego duchem.

3. symboliczna (aksjologiczna) - jej treścią są zasoby niedostępne $\mathrm{W}$ bezpośrednim doświadczeniu. To wartości, normy, ustroje stymulujące innowacyjność na poziomie zarówno jednostkowym, jak i całości społecznej. Konceptualnym zapleczem tejże warstwy są ustalenia badaczy zmierzających w stronę diagnozowania aksjologii kultur gospodarczych. Zaliczyć do nich trzeba: Maxa Webera (1994), opisującego zróżnicowania gospodarcze Europy w kontekście protestanckiej idei predestynacji; Shumela Eisenstadta (2009), dokonującego podziału cywilizacji na aksjalne i nieaksjalne; Ronalda Inglharta (2003), dzielącego świat w na kultury ekspansji i przetrwania, czy wreszcie Miguela Basáñeza (2016), proponującego rozdzielić ziemie pomiędzy odmienne zestawy wartości, powiązane z honorem, motywacją osiągnięć i radością. Warstwa symboliczna dopinguje do tego, aby innowacyjność traktować w sposób pozainstrumentalny, jako wyzwanie dla jednostki i systemu społecznego. W tej perspektywie innowacyjność wymaga dwóch różnych form legitymizacji: poznawczej i normatywnej. Wspiera się ona nie tylko na sprawności intelektualnej i manipulacyjnej, ale przede wszystkim potrzebuje pielęgnacji cnót społecznych, takich jak: odwaga, wytrwałość, pracowitość. Stawia jednocześnie przed jednostką wymóg elastyczności umysłowej, a od systemu domaga się strukturalnego dopasowania. Staje się przez to szansą i zagrożeniem; wyzwaniem i problemem. I w tym też tkwi jej specyfika.

Dodatkowo kultura innowacyjności może się realizować na dwóch różnych poziomach: jednostkowym i systemowym. $Z$ jednej strony nowatorstwo jest dziełem konkretnego człowieka, wyczynem jednostki wybitnej i szczególnie utalentowanej, kierującej się w swych działaniach hubris - właściwą gatunkowi ludzkiemu pychą tworzenia (Kozielecki, 2002, s. 39). Z drugiej natomiast innowacyjność jest wytworem systemowym, dzieckiem epoki, swoich czasów. Powstaje w konkretnych uwarunkowaniach gospodarczych, historycznych 
i społecznych. Jak przekonuje William Ogburn, wszelcy innowatorzy są "dziećmi swoich" czasów, ich reprezentantami. Wielcy ludzie w myśl tych ustaleń - dają się opisać jako wykonawcy przydzielonych im ról. Są wytworami danych społeczeństw (Ogburn, 1946, s. 33-43). Powołuje ich do istnienia system społeczny oraz obecne w nim wartości, obowiązująca struktura awansu, sposób sprawowania władzy i wiele innych zmiennych (Gradona 2003).

\section{TYPOLOGIA KULTUR INNOWACYJNOŚCI JAKO NARZĘDZIE SYSTEMATYZACJI}

Kategorie wielowymiarowe - a do takowych należy tytułowa kultura innowacyjności - wymagają typologicznej analizy. Pozwala ona bowiem objąć swym zakresem szerokie spectrum zjawisk związanych z analizowaną kategorią i dotrzeć do wszystkich obszarów pojęcia. Wskazane $\mathrm{w}$ typologii typy mają charakter konceptualny, toteż rzeczywistość może być jedynie do nich porównywana i „diagnozowana" za sprawą zaobserwowanego odstępstwa. Jednocześnie zaprezentowana typologia pozwala na identyfikację różnych odmian kultur innowacyjności, co z kolei umożliwia wskazanie szans i zagrożeń dla poszczególnych typów.

Zestawienie w tabeli krzyżowej poziomów i warstw analizy pozwala wyróżnić cztery podstawowe kultury innowacyjności: eksperymentu, laboratorium, indywidualnej inicjatywy, skoordynowanego działania, poświęcenia i zbiorowego posłannictwa.

Tabela 1

Typy kultur innowacyjności

\begin{tabular}{|l|l|l|l|}
\hline $\begin{array}{l}\text { Poziom analizy/ } \\
\text { warstwa kultury }\end{array}$ & \multicolumn{1}{|c|}{ Materialny } & \multicolumn{1}{|c|}{ Społeczny } & Symboliczny \\
\hline Jednostkowy & $\begin{array}{l}\text { kultura } \\
\text { eksperymentu }\end{array}$ & $\begin{array}{l}\text { kultura indywidualnej } \\
\text { inicjatywy }\end{array}$ & kultura poświecenia \\
\hline Systemowy & $\begin{array}{l}\text { kultura } \\
\text { magamaszyny }\end{array}$ & $\begin{array}{l}\text { kultura skoordynowanego } \\
\text { działania }\end{array}$ & $\begin{array}{l}\text { kultura zbiorowego } \\
\text { posłannictwa }\end{array}$ \\
\hline
\end{tabular}

Źródło: opracowanie własne.

Kultura eksperymentu powstaje poprzez skrzyżowanie warstwy materialnej z poziomem jednostkowym, przez co znajduje 
wyraz z zindywidualizowanej, nierzadko wręcz odosobnionej pracy wynalazczej. Jej miarą są wszelkie wytwory działalności technologicznej i naukowej człowieka, które przyjmują postać wynalazków technologicznych i społecznych, jak również odkryć prowadzących do ich skonstruowania, wdrożenia lub udoskonalenia. W ten też sposób obszar „materialny" rozszerza się o odkrycia związane z diagnostyką obszaru materii. Kwintesencją kultury eksperymentu jest jednak właściwy jej indywidualizm. To jednostka - w zaproponowanym przez kulturę eksperymentu układzie - obciążona zostaje powinnością sięgania po novum. Do nowatorstwa dochodzi się w tej kulturze samodzielnie, niemal po „partyzancku”, bez systemowego wsparcia, zaplecza instytucjonalnego i organizacyjnego (Zdun, 2018, s. 63). W kulturze eksperymentu innowacyjność realizuje się za to z wielkim sukcesem, eksponując "gatunkową wyjątkowość" człowieka, która sprowadza się do wytwarzania ogromnej liczby narzędzi w sposób intencjonalny, tj. za sprawą konceptualnego oddzielenia środków od celów (Tomassello, 2002, s. 9). Dodatkowo kultura ta unaocznia fakt, że homo sapiens jest zdolny do utrwalania swoich eksperymentów w czasie - przekazując odkrycia kolejnym pokoleniom w procesie społecznego uczenia się. Kultura eksperymentu ma swój początek w penetrowaniu natury i służy rozładowaniu napięć motywacyjnych jednostki (Kozielecki, 2002, s. 28-29). Pozostawia jednak jednostkę w osamotnieniu, zamkniętą w laboratorium, gdzie człowiek, zdając się wyłącznie na własną inicjatywę i talenty, może dokonywać przełomowych odkryć. $W$ takim też przybytku - w ślad za wielkim Leonardem - istota ludzka doświadcza mocy i renesansowego przekonania o wyjątkowości swej natury.

Kultura megamaszyny powstaje poprzez skrzyżowanie warstwy materialnej z poziomem systemowym. Dlatego też daje się rozpoznać jako rozwinięcie kultury eksperymentu. Wychodzi ona bowiem z propozycją wsparcia, ale i ograniczenia i kontrolowania jednostek. Z jednej strony wynalazczość zostaje wyprowadzona z laboratorium; z drugiej - musi podporządkować się polityce instytucji wspierającej. W tym też kontekście Lewis Mumford (2012, s. 63) pisze o megamaszynie - społecznym reżymie organizującym działalność innowacyjną człowieka. Megamaszyna zaczyna dysponować własnym wyposażeniem technicznym, staje się organizacją społeczną która zagospodarowuje „warstwę materialną" i koordynuje działania w jej sferze. Warstwa ta zaczyna podlegać konkretnej władzy. 
Megamaszynami początkowo rządzili faraonowie i królowie. Później urzeczywistnień megamaszyny trzeba było szukać za murami benedyktyńskich i cysterskich opactw. To one w Wiekach Średnich pełniły rolę przedprzemysłowej manufaktury (Eberl, 2011, s. 206-216).

Kultura indywidualnej inicjatywy powstaje na przecięciu warstwy społecznej z wymiarem jednostkowym. Kluczową kategorią w tym typie kultury jest „duch przedsiębiorczości”, działanie człowieka tak mocno eksponowane w pracach Maxa Webera (1994) i Josepha Schumpetera (1960). Innowacyjność w tej kulturze wspiera się na jednostkowej inicjatywie, aktywności, indywidualnej motywacji do pracy. Wymaga wytrwałości, umiejętności poruszania się po świecie, tworzenia sieci kontaktów, ale już nie wynalazczego geniuszu. Domaga się od innowatora określonych cech osobowości i skłonności do podejmowania ryzyka. Z tej też przyczyny do rangi najwyższej wynosi kwestię motywacji do przekształcania świata, bycia lepszym od innych. Jednocześnie ten typ kultury dysponuje konkretną nagrodą, zachętą do podejmowania się trudu innowacyjności. Jest indywidualny zysk, mierzony gratyfikacją materialną i symboliczna, pieniędzmi i prestiżem osiągniętego stanowiska.

Kultura skoordynowanego działania stanowi systemowe przekształcenie „,kultury indywidualnej inicjatywy”. Jest efektem skrzyżowania poziomu systemowego z warstwą symboliczną. Dlatego też kwintesencją tej kultury jest depersonalizacja innowacyjności. Kultura ta nie poszukuje już bohaterów nowatorstwa i nie dąży do tego, by ich stwarzać. W jej interesie jest raczej systemowe "produkowanie" novum. Przez to też wyróżnikiem kultury skoordynowanego działania jest systemowa polityka innowacyjności, realizująca się zarówno w postaci programów wsparcia, jak również działań ukierunkowanych na wykreowanie „ustroju” przychylnego nowatorstwu. Kwintesencją systemu jest bowiem ład określający sposób jego funkcjonowania, w tym też reakcję na „osobliwość" - to co odmienne i nowatorskie. Wiesław Gumuła (2008, s. 57) wyróżnia cztery typy ustrojów całości społecznej, biorąc pod uwagę dwie kluczowe zmienne: tolerancję struktur pospolitych względem innowacji oraz odporność struktur na inwazję novum. Wskazane przez niego rodzaje ustrojów to systemy:

1. Wysokiej tolerancji oraz dużej odporności na osobliwości (ustroje otwarte)- to system względnie przychylny wobec nowatorstwa. Pozwala mu zaistnieć, 
ale utrudnia sposób rozpowszechniania. W takim ustroju powstają "wyspy nowatorstwa”.

2. Wysokiej tolerancji osobliwości oraz małej odporności na osobliwości (ustroje odkryte, przejściowe) - to ustrój podatny na innowacje i pozwalający na szybki sposób ich rozpowszechniania. Ma elastyczną strukturę, odpowiada na sygnały napływające z zewnętrznego środowiska.

3. Niskiej tolerancji osobliwości oraz dużej odporności na osobliwości (ustroje autarkiczne) - to ustrój, który walczy z przejawami nowatorstwa, jego struktura jest nieelastyczna i odporna na przebudowę; ma za to mechanizmy eliminujące zagrażanie $\mathrm{w}$ postaci novum.

4. Niskiej tolerancji osobliwości oraz małej odporności na osobliwości (ustroje zamknięte)to ustrój nieprzychylny nowatorstwu, ale jednocześnie niedysponujący instrumentarium, dzięki któremu mógłby innowacyjność eliminować.

Kultura poświęcenia powstaje poprzez skrzyżowanie poziomu indywidualnego z warstwą symboliczna, dlatego też na plan pierwszy wysuwa kwestię norm i wartości. Działalność innowacyjna staje się tu misją wartą wyrzeczeń, a nawet i poświęcenia. Kultura poświęcenia realizuje się $\mathrm{w}$ prometeizmie, a jej nadrzędną kategorią jest misja. Przez to też potrzebuje bohaterów pracujących w imię etosu innowacyjności. Do grupy jej herosów zaliczyć trzeba m.in. Marię Skłodowska-Curie, która umierając na popromienną chorobę nowotworową dowodzi, że Prometeusza zabija to, co jednocześnie czyni nieśmiertelnym. Sednem kultury poświęcenia jest transgresja indywidualna ukierunkowana jednak nie na zysk, konkretny cel, ale raczej na czynienie świata doskonalszym, odrobinę lepszym. Stawia ona przez to jednostkę przed pokusą wchodzenia w obszary niebezpieczne. Dziś te „wycieczki” realizują się pod hasłem transhumnaizmu i ukierunkowane są na formowanie modelu postczłowieka - istoty zdolnej do życia dłuższego, bezpieczniejszego i intensywniejszego. Działania te nierzadko godzą w ludzką naturę i każą zadać pytanie o granice w badaniach i nauce. $W$ ten też sposób obnażają założenia współczesnego humanizmu, który działając na rzecz człowieka ostatecznie uderza w jego naturę. 
Kultura zbiorowego posłannictwa stanowi systemowe rozwinięcie kultury poświecenia. $Z$ tej też przyczyny jej wyróżnikiem jest systemowy „katechizm” nowatorstwa. Ukierunkowana jest ona na wykreowanie „aksjologii innwacyjności”, zestawu rozpowszechnionych w systemie norm i wartości, które powoływać będą do istnienia innowacyjne inicjatywy. Innymi słowy: w kulturze zbiorowego posłannictwa nowatorstwo staje się zagadnieniem „misyjnym”. System jest całością etosową powołaną do wdrażania rozwiązań udoskonalających świat. Takim też aksjologicznym projektem było Aleksandryjskie Muzeum - pierwsza w historii ludzkości instytucja wynalazcza. Pracowali w niej tacy uczeni jaki Starton i Archimedes (Burke i Orstein, 1999, s. 33). Była to nie tylko pierwsza innowacyjna placówka, kontrolowana i finansowana przez państwo, ale również wcielenie konkretnych założeń filozoficznych: typowej dla filozofii greckiej racjonalności oraz idei kalokagathia - poszukiwania harmonii ducha i ciała. Innowacyjność w Muzeum stanowiła wyzwanie dla ducha. Służyła nie tylko obszarowi praxis, ale objęła również swym zakresem dogmat. Urosła do rangi moralnego obowiązku. Kwestię tę, w sposób jeszcze bardziej wyrazisty, podnosi oświeceniowy empirysta Franciszek Bacon. W dziele Novum Organum stwierdza, że powinnością nauki powinno być wytwarzanie wynalazków (Bacon, 1955, s. 105). By jednak było to możliwe, powołać trzeba do istnienia świat sprzyjający nowatorstwu. Jest nim Nowa Atlantyda. To republika uczonych, świat w którym innowacyjność jest nie tylko wspierana przez świetnie doposażone laboratoria, ale staje się również przedmiotem publicznej troski. Kompetencje naukowe i moralne w Nowej Atlantydzie wzajemnie się uzupełniaja, a nowatorstwo staje się zbiorowym posłannictwem. Współcześnie „Nowa Atlantyda” staje przed pokusą "zaostrzenia kursu”, a to prowadzić może do „przewartościowania innowacyjności”, w drodze transformacji - ,aksjologię nowatorstwa” w „innowacyjną dyktaturę" (Zdun, 2017, s. 180).

\section{WYNIKI ANALIZY: UNIWERSYTET I KULTURA INNOWACYJNOŚCI}

Typologia kultur innowacyjności ostatecznie służyć ma diagnozie współczesnego uniwersytetu, dookreśleniu jego szans i zagrożeń. 
Diagnozę tę poprzedzić musi określenie miejsca uniwersytetu w dzisiejszym świecie. Jest to instytucja, która ma wielkie dziedzictwo. Pozytywnie wartościowana cześć tego dziedzictwa to tradycja. Uformowała się ona wokół kilku kluczowych kategorii: wolności, prawdy i racjonalności. Wartości te wymagają od akademików pielęgnacji konkretnych społecznych cnót, m.in.: pracowitości, roztropności, rzetelności, umiarkowania, od wagi. Za ich sprawą uniwersytet daje się opisać jako „królestwo wartości” (Stróżewski, 1992, s. 23). Jest próbą urzeczywistnienia założeń Aleksandryjskiego Muzeum czy też „Nowej Atlantydy”. Wartości nie zwalniają jednak uniwersytetu $\mathrm{z}$ reakcji na bodźce napływające $\mathrm{z}$ otoczenia.

Gospodarka oparta na wiedzy i innowacyjności wysyła w stronę uniwersytetu konkretne zamówienia, nierzadko domagając się rezygnacji ze szczytnych idei. Realizując te wymogi akademia miałaby pozbawić się własnej tożsamości i przekształcić w fabrykę nowatorstwa, zasilająca gospodarkę przemyślnymi rozwiązaniami. W rezultacie zmuszona zostałaby do rezygnacji ze swojej zasadniczej funkcji związanej z rozwijaniem potencjału człowieczeństwa i budowaniem wspólnoty etosu wiedzy (Bochenek, 2006, s.27). By tym efektom zapobiec, a jednocześnie wywiązać się z zadań stawianych przez otoczenie, "uniwersytet powinien być świadomy” zagrożeń i szans, jakie stwarzają dlań konkretne kultury innowacyjności.

I tak okazuje się, że podstawowym mankamentem kultur indywidualistycznych (eksperymentu, indywidualnej inicjatywy, poświęcenia) jest efekt „badawczego osamotnienia”. Osamotnienie to skutkować może podejmowaniem się przez jednostkę „zadań ponad siły", bez jakiegokolwiek wsparcia. Efektem tego typu działań jest marnotrawstwo indywidualnych talentów. Jednocześnie praca skrajnie zindywidualizowana ogranicza zdolność dyfuzyjną novum. To uniwersytet winien brać udział w działaniach wdrożeniowych i działaniach popularyzacyjnych, choć przez wieki odżegnywał się od tej roli. Uniwersytety jako "twierdze skostniałej scholastyki" przez dziesiątki, jak nie setki, lat odmawiały wsparcia nowatorstwu (Höffe, 2002, s. 125) i wydają się być do tej roli przyzwyczajone. Dopiero propozycja oświeceniowych empirystów zaowocowała powołaniem instytucji, takich jak Towarzystwo Naprawy Wiedzy Przyrodniczej (Burke i Orstein, 1999, s. 143). Odpowiadały one nie tylko za wspieranie innowacyjności, ale również „egzaminowały” ją poznawczo 
i normatywnie. Z legitymizacją normatywną wiąże się kolejne ustalanie na temat „innowacyjnego osamotnienia”. Stawia ono jednostkę przed pokusą wykonywania badań na granicy praworządności. To uniwersytet winien kontrolować nowatorstwo pod względem zasad etycznych, nie dopuszczając metod godzących w kluczowe dla akademii wartości.

Właściwe dla kultur indywidualistycznych „osamotnienie” ogranicza „wspólnotowość" uniwersytetu. Indywidualizm sprawia, że akademia staje się obszarem realizowania kariery. Tym samym „kultura osamotnienia" stwarza model naukowca samowykluczającego się z akademickiej wspólnoty, żyjącego życiem własnych grantów, indywidualnymi zyskami, naukowym sukcesem. Dodatkowo model ten może poddać się procesowi wulgaryzacji. Wtedy też ciekawość świata zostanie zastąpiona motywacją do osiągania tanich zwycięstw i tymczasowych triumfów. Wersja wysublimowana tejże kultury pozwala jednak na samorealizację, dokonywanie śmiałych odkryć i doświadczanie osobistych transgresji. Kultury indywidualistyczne, we wszystkich swych odmianach, legitymizują podejmowanie się przedsięwzięć, do których nie mieliby talentu, odwagi i zapału inni. I w tym tkwi jej siła.

Z kolei „uspołecznione kultury innowacyjności” stawiają uniwersytet przez pokusą „,skoszarowania innowacyjności”. „Skoszarowanie" to przyjmować może dwie podstawowe formy: ograniczenia i dyktatury. Oba zjawiska wynikają z ustroju i aksjonormatywnego ładu przyjętego w uniwersyteckiej całości społecznej. W przypadku pierwszym, akademia nie wspiera nowatorskich inicjatyw lub też im przeciwdziała. Takie ustosunkowanie uniwersytetu potwierdzają doświadczenia historyczne, czasy w których akademia - powtórzmy raz jeszcze - była "ś́wiątynią scholastyki”, strażnikiem rygorów moralnych, narzuconych przez ówczesny światopogląd. Uniwersytet taki cechował się strukturą skostniałą i nieelastyczna, przeciwstawiającej się wszelkiej „osobliwości”. Współcześnie, ustrój zamknięty realizuje się pod hasłem skrajnej biurokratyzacji, która przeszkadza pracy odkrywczej, wymagając od naukowca podjęcia się zajęć właściwych dla wykwalifikowanego urzędnika. Z kolei „dyktatura innowacyjności" to taka polityka akademii, która transformuje uniwersytet $\mathrm{w}$ manufakturę innowacji. Polityka ta posługuje się różnymi rygorami nowatorstwa, lubi wskaźniki i tabele, zmierza w stronę 
zwiększenia produktywności patentowej. Temu też służą „narracje grantowe”, których celem nierzadko jest wykazanie „stosowalności nawet tego, co niestosowalne".

Uniwersytet pracujący w trybie „innowacyjnej dyktatury” wymusza podejmowanie się badań o charakterze aplikacyjnym i zacieśnianie współpracy z gospodarką. Przez to też deprecjonuje znaczenie dyscyplin, które z natury rzeczy, współpracą taką wykazać się nie mogą. „Uspołeczniona kultura innowacyjności” może jednak oprzeć się procesowi wulgaryzacji i zmierzać w stronę wykreowania „środowiskowego optimum" dla naukowego nowatorstwa. Ustrój takiej akademii nie może posługiwać się ani dyktatem, ani blokadą. Powinien za to manipulować narzędziami stymulującymi nowatorstwo i stać się inkubatorem innowacyjności. Osiągnąć to może poprzez uelastycznienie swojej struktury, ograniczenie biurokracji oraz organizacyjne i finansowe wspomaganie projektów badawczych. Ustrój proinnowacyjny powinien dysponować właściwym mechanizmem motywacyjnym i gratyfikacyjnym, znajdującym odzwierciedlenie w jasnych i sprawiedliwych ścieżkach awansu dla innowatorów. System taki jednocześnie nie powinien czuć się zwolniony z nadzorowania innowacyjności. Winien dookreślać jej reguły gry i odróżniać nowatorstwo rzeczywiste, znajdujące zastosowanie w obszarze gospodarczym, technologicznym czy społecznym od nowatorstwa sztucznie uzasadnianego, wyłącznie na potrzebę uzyskania finansowania konkretnego projektu.

\section{WNIOSKI I REKOMENDACJE}

Wyniki niniejszej analizy pozwalają na koniec przedstawić proste rekomendacje dla uniwersytetu. Są one rezultatem konfrontacji modelów indywidualistycznych i systemowych kultury innowacyjności. Modele te w pewnym sensie są sobie przeciwstawne. Ujęcie jednostkowe akcentuje kwestię roli, motywacji i działań aktorów społecznych. Z kolei perspektywa systemowa eliminuje jednostkę z kultury innowacyjności na rzecz ekspozycji kategorii ustroju. Te dwa „punkty widzenia" odpowiadają podziałowi na atomizm i holizm w teorii socjologicznej i w zupełnie inny sposób diagnozują rzeczywistość społeczną. Atomizm przecenia jednostkę, a holizm - zbyt mocno 
wierzy system. Lukę konceptualną pomiędzy tymi ujęciami wypełniają koncepcje z zakresu tzw. ,"trzeciej socjologii” (Sztompka, 2016). Jedną z nich jest teoria podwójnej morfogenezy autorstwa Margaret Archer (2013). Zgodnie z tą teorią działaniem jednostki kierują troski osobiste, które jednak ulec muszą systemowemu przepracowaniu. Oznacza to, że nie mogą się „rozzuchwalić” i podlegają mechanizmowi systemowego ograniczenia. Jednocześnie okazuje się, że system nie ma absolutnej władzy nad jednostką. Stwarza jedynie ramy jej działania. Jednostka odbiera sygnały płynące od systemu i wykonuje przypisane jej zadania w sposób zindywidualizowany, z uwzględnieniem własnych trosk. I takiemu „zabiegowi podwójnej morfogenezy” winien poddać się współczesny uniwersytet. Wtedy też stworzy swobodę dla transgresji indywidualnych, a jednocześnie nie pozwoli „zwulgaryzować się" indywidualizmowi. Nie będzie też mógł odgrywać roli „systemu opresyjnego", który posługuje się wobec aktorów społecznych dyktatem. W zamian za to nauczy się rozpoznawania „indywidualny trosk” badaczy. I wtedy też da się rozpoznać jako projekt aksjologiczny par excellence, utopijna i wyśniona przez Franciszka Bacona „Nowa Atlantyda”.

\section{Bibliografia}

Archer, M. (2013). Człowieczeństwo. Problem sprawstwa. Kraków: Nomos. Bacon, F. (1955). Novum Organum. Przeł. J. Wikarjak. Warszawa: Państwowe Wydawnictwo Naukowe.

Barnett, H. (1953). Innovation: The Basis of Cultural Change. New York: McGraww-Hill Company.

Basáñez, M.E. (2016). A World of Three Cultures: Honor, Achievement and Joy. Oxford: Oxford University Press.

Bochenek, K. (2006). Personalistyczny kontekst wizji uniwersytetu w refleksji Karola Wojtyły. W: W. Furmanka (red.), Idea uniwersytetu w nauczaniu Jana Pawła II (13-30). Rzeszów: Wydawnictwo Uniwersytetu Rzeszowskiego.

Burke, J., Orstein, R. (1999). Ostrze geniuszu. Obosieczne skutki rozwoju cywilizacji. Przeł. M.Sachnowski. Warszawa: Philip Wilson.

Eberl, I. (2011). Cystersi. Historia zakonu europejskiego, przeł. P. Włodyga. Kraków: Wydawnictwo Astraia.

Eisenstadt, S. (2009). Utopia i nowoczesność. Porównawcza analiza cywilizacji. Przeł. Adam Ostolski. Warszawa: Oficyna Wydawnicza. 
Grandona, M. (2003). Kulturowa typologia rozwoju gospodarczego, przeł. S. Dymczyk. W: L.E. Harrison, S.P. Huntington (red.), Kultura ma znaczenie. Jak wartości wpływaja na rozwój społeczeństw (101-116). Poznań: Wydawnictwo Zysk i S-ka.

Gumuła, W. (2008). Teoria osobliwości społecznych. Zaskakująca transformacja $w$ Polsce. Warszawa: Wydawnictwo Naukowe Scholar.

Hagen, E. (1962). On the Theory of Social Change. How Economic Growth Begins. Homewood: The Dorsey Press Inc.

Höffe, O. (2004). Mała historia filozofii. Przeł. J. Sidorek. Warszawa: Wydawnictwo Naukowe PWN.

Inglehart R. (2003). Kultura a demokracja, przeł. S. Dymczyk. W: L.E. Harrison, S.P. Huntington (red.), Kultura ma znaczenie. Jak wartości wptywają na rozwój społeczeństw (146-168). Poznań: Wydawnictwo Zysk i S-ka.

Kłoskowska, A. (2007). Socjologia kultury. Warszawa: Wydawnictwo Naukowe PWN.

Kozielecki J. (2002). Transgresja i kultura. Warszawa: Wydawnictwo Akademickie Żak.

McClelland, D. (1961). The Achieving Society. Princeton: Van Nostrand.

Mumford, L. (2012). Mit maszyny. Pentagon wiedzy, t. 1. Przeł. M. Szczubiałka. Warszawa: Wydawnictwo Naukowe PWN.

Ogburn, W.F. (1964). On Culture and Social Change. Selected papers. Edited and with an Introduction by Otis Dudley Duncan. Chicago: University Press Chicago.

Rogers, E. (1983). Diffusion of Innovations. New York: The Free Press.

Schumpeter, J. (1960). Teoria rozwoju gospodarczego. Przeł. J. Grzywicka. Warszawa: PWN.

Sombart, W. (1919). Der moderne Kapitalismus. Historisch-systematische Darstellung des Gesamten Eropäischen Wirtschaftsleben von Seine Anfrägen bis zur Gegenwart. München: Duncker \& Humblot.

Stróżewski, W. (1992). W kręgu wartości. Kraków: Znak.

Szacki, J. (2012). Historia myśli socjologicznej. Wydanie Nowe. Warszawa: Wydawnictwo Naukowe PWN.

Sztompka, P. (2016). Kapitał społeczny. Teoria przestrzeni międzyludzkiej. Kraków: Wydawnictwo Znak.

Tomasello, M. (2002). Kulturowe źródła ludzkiego poznania. Przeł. J. Rączaszek. Warszawa:

Weber, M. (1994). Etyka protestancka a duch kapitalizmu. Przeł. J. Miziński. Lublin: Wydawnictwo Test.

Zdun, M. (2017). Oblicza innowacyjności. Socjologiczna próba typologizacji zjawiska. Prakseologia, 159, 161-185. 
Zdun, M. (2016). Innowacyjność jako kategoria analityczna zmiany społecznej. O dychotomicznej naturze pojęcia. Studia Socjologiczne, 2(221), 163-185.

\section{Copyright and License}

This article is published under the terms of the Creative Commons Attribution - NoDerivs (CC BY- ND 4.0) License http://creativecommons.org/licenses/by-nd/4.0/ 